Article

\title{
Ion-Conductive Nanostructured Polymer Films Formed by Photopolymerization of Lyotropic Columnar Liquid-Crystalline Monomers, Composed of a Zwitterionic Compound and a Protic Ionic Liquid
}

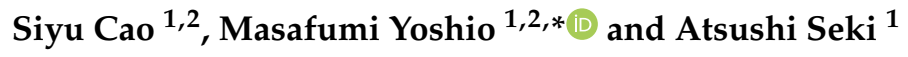 \\ 1 Center for Functional Sensor \& Actuator, Research Center for Functional Materials, National Institute for \\ Materials Science, 1-1 Namiki, Tsukuba, Ibaraki 305-0044, Japan; CAO.Siyu@nims.go.jp (S.C.); \\ Seki.Atsushi3@nims.go.jp (A.S.) \\ 2 Graduate School of Chemical Sciences and Engineering, Hokkaido University, Kita 13, Nishi 8, Kita-ku, \\ Sapporo, Hokkaido 060-8628, Japan \\ * Correspondence: YOSHIO.Masafumi@nims.go.jp; Tel.: +81-29-860-4728; Fax: +81-29-860-4718
}

Received: 19 March 2020; Accepted: 3 April 2020; Published: 6 April 2020

\begin{abstract}
Here, we report on a new family of columnar nanostructured polymer films forming protic nanochannels that exhibit good ionic conductivities in the order of $10^{-4}-10^{-3} \mathrm{~S} \mathrm{~cm}^{-1}$ at ambient temperature. These polymer films were obtained by the in situ photopolymerization of lyotropic columnar liquid crystals, consisting of a polymerizable taper-shaped zwitterionic compound and a protic ionic liquid (imidazolium bis(trifluoromethylsulfonyl)imide), in the presence of $15 \mathrm{wt} \%$ water. The composition of the protic ionic liquid in the mixture was changed from 40 to $60 \mathrm{~mol} \%$. The ionic conductivities were measured by an alternating current impedance method. The ionic conductivity increased with the increase of the protic ionic liquid. The conductivities of columnar nanostructured polymer films were about 2-3 orders of magnitude higher than those of amorphous polymer films prepared by photopolymerization of the corresponding monomers in an isotropic liquid state. The formation of nanochannels in the polymer matrices significantly enhanced the ion conduction. The present two-component lyotropic liquid-crystalline self-assembly followed by photopolymerization is a promising approach to the development of high ion-conductive polymer membranes.
\end{abstract}

Keywords: lyotropic liquid crystals; ionic liquids; nanochannels; zwitterionic compounds; ion-conductive materials

\section{Introduction}

Nanostructured ionic liquid-crystalline (LC) assemblies are currently attracting widespread interest for applications in batteries and separation membranes [1-8]. Our intension herein is to develop columnar LC polymer electrolytes, forming proton transport highways which will pave way to better fuel cells and ion-conducting polymer actuators [9]. We previously reported on the development of proton transporting columnar and bicontinuous cubic LC assemblies with one-dimensionally anisotropic channels and three-dimensionally interconnected channels, respectively $[10,11]$. These materials were obtained by co-assembly of zwitterionic LC molecules and Brønsted acids or dihydroxy-functionalized LC molecules and protic ionic liquids. The nanosegregation and intermolecular interactions play a great key role in controlling the self-organized nanostructures and enhancing proton transport. We wonder if the co-assembly of zwitterionic molecules and more mobile protic ionic liquids can induce the LC phases at ambient temperature and enhance the proton conductivity. The binary mixtures of solid imidazolium-based zwitterionic salt and 
bis(trifluoromethylsulfonyl)imide acid (HTFSI) were reported to form ambient temperature ionic liquids by Yoshizawa and Ohno [12]. This concept was further extended to the design of high proton-conductive thermotropic and lyotropic LC materials [13-16]. In addition, Watanabe and coworkers developed high proton-conducting protic ionic liquids by the neutralization of imidazole and HTFSI, which can be applicable to fuel cell electrolytes [17]. Therefore, we assume that the self-assembly of protic ionic liquids containing TFSI anion and taper-shaped polymerizable zwitterionic molecules into columnar LC phases and the subsequent photopolymerization could produce prominent nanostructured polymer films preserving the fluidic proton transport highways in the solid matrices (Figure 1).

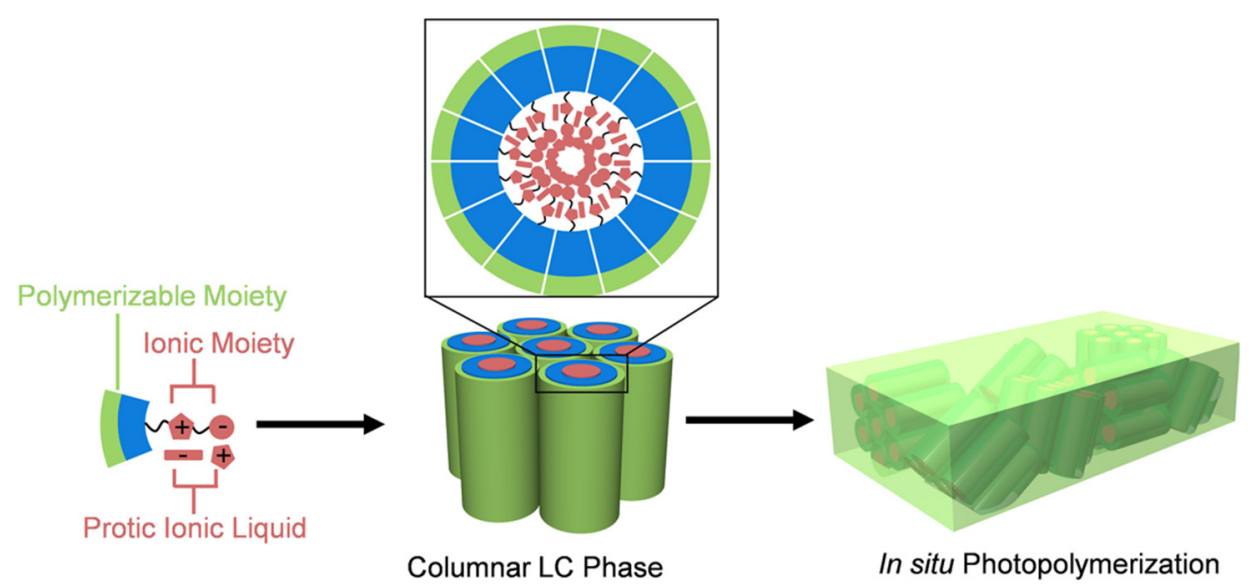

Figure 1. Schematic illustration of the columnar LC self-assembly of polymerizable zwitterionic compound, protic ionic liquid, and water and fabrication of polymer film with one-dimensionally proton-conductive nanochannels by in situ photopolymerization.

Here, we report on a new family of proton-conductive columnar LC polymer films based on room-temperature lyotropic columnar LC monomers composed of a zwitterionic molecule $\mathbf{1}$ having three acrylate groups at the extremity of the alkyl chains, protic ionic liquid 2, and water (Figure 2). The incorporation of a larger content of ionic liquid into the center of the columns has successfully provided a highly ion-conductive polymer film with mechanical robustness.

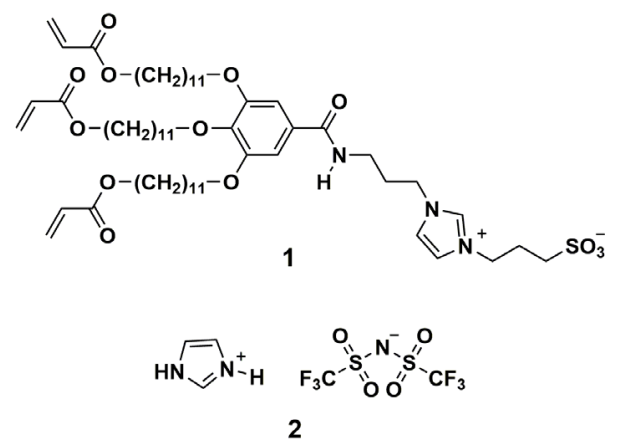

Figure 2. Chemical structures of polymerizable taper-shaped zwitterionic molecule $\mathbf{1}$ and protic ionic liquid 2.

\section{Experimental Section}

\subsection{General Procedures and Materials}

All ${ }^{1} \mathrm{H}$ NMR spectra were recorded on a JEOL JNM-AL30/BZ spectrometer at $300 \mathrm{MHz}$ for solutions in $\mathrm{CDCl}_{3}$ or $\mathrm{D}_{2} \mathrm{O}$. The chemical shifts $(\delta)$ are quoted in ppm using tetramethylsilane $(\delta=0.00)$, as the internal standard for $\mathrm{CDCl}_{3}$ solutions and a solvent residual peak $(\delta=4.79)$ for a $\mathrm{D}_{2} \mathrm{O}$ solution. All 
${ }^{13} \mathrm{C}$ NMR spectra for $\mathrm{CDCl}_{3}$ solutions were recorded on JEOL ECZ400S at $100 \mathrm{MHz}$, using the solvent peak as internal reference $(\delta=77.0)$. High-resolution mass spectrometry (HRMS) measurements were carried out by using a BRUKER microTOF II. FT-IR spectra were taken with a BRUKER FT-IR ALPHA II spectrometer with a single reflection diamond ATR module. Elemental analysis for CHNS was carried out by using an ELEMENTAR vario EL cube. All reagents were purchased from Sigma-Aldrich, Tokyo Chemical Industry, Kanto Chemicals, and Wako Pure Chemical Industries and used without further purification.

\subsection{Synthesis}

Zwitterionic compound 1 was synthesized according to the procedures shown in Scheme 1. Intermediate compound 3 was prepared by the condensation reaction of tris(11'-acryloyloxyundecyl oxy)benzoic acid [18] and 1-(3-aminopropyl)imidazole. Protic ionic liquid 2 was obtained by the reaction of HTFSI and imidazole in the modified synthetic procedure [19].
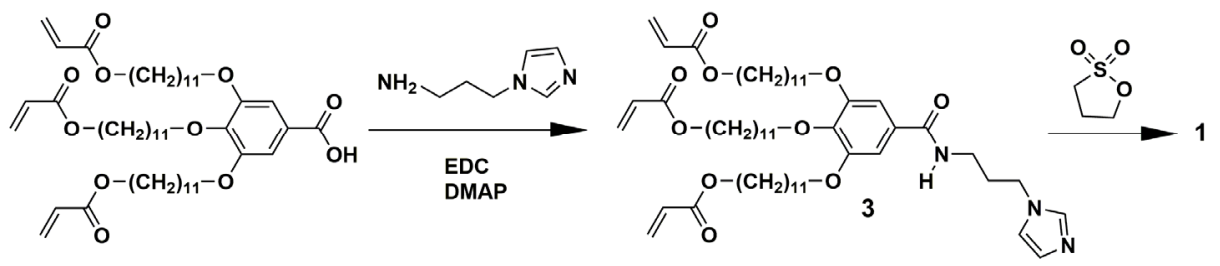

Scheme 1. Synthetic route of compound 1.

Synthesis of Compound 3

In the synthesis, 1-(3-aminopropyl)imidazole $(0.46 \mathrm{~g}, 3.70 \mathrm{mmol})$ was added dropwise to a dry dichloromethane solution $(10 \mathrm{~mL})$ of tris(11'-acryloyloxyundecyloxy)benzoic acid (1.56 g, $1.85 \mathrm{mmol})$, 4-(dimethylamino)pyridine (DMAP) $(0.02 \mathrm{~g}, 0.20 \mathrm{mmol})$ and 1-ethyl-3-(3-dimethylaminopropyl) carbodiimide hydrochloride (EDC) $(0.71 \mathrm{~g}, 3.70 \mathrm{mmol})$ in a light-resistant three-necked round-bottom flask at $0{ }^{\circ} \mathrm{C}$. The reaction mixture was warmed to room temperature and stirred for $18 \mathrm{~h}$. The solvent was removed by evaporation. The residue was purified by flash column silica gel chromatography using an eluent of $\mathrm{CHCl}_{3} / \mathrm{MeOH}=95 / 5$ to give compound $3(1.28 \mathrm{~g}, 1.35 \mathrm{mmol}, 73 \%$ yield $)$ as a white solid.

${ }^{1} \mathrm{H} \mathrm{NMR}\left(300 \mathrm{MHz}, \mathrm{CDCl}_{3}\right): \delta[\mathrm{ppm}]=7.52(\mathrm{~s}, 1 \mathrm{H}), 7.07(\mathrm{~s}, 1 \mathrm{H}), 6.97(\mathrm{~s}, 1 \mathrm{H}), 6.92(\mathrm{~s}, 2 \mathrm{H}), 6.39$ $(\mathrm{dd}, J=17.2,1.5 \mathrm{~Hz}, 3 \mathrm{H}), 6.12(\mathrm{dd}, J=17.2,10.3 \mathrm{~Hz}, 3 \mathrm{H}), 5.80(\mathrm{dd}, J=10.3,1.5 \mathrm{~Hz}, 3 \mathrm{H}), 4.14(\mathrm{t}, J=6.8 \mathrm{~Hz}$, $6 \mathrm{H}), 4.08-3.96(\mathrm{~m}, 7 \mathrm{H}), 3.46\left(\mathrm{q}, J=6.4 \mathrm{~Hz}, 2 \mathrm{H}, 2.16(\mathrm{~m}, 2 \mathrm{H}), 1.85-1.59(\mathrm{~m}, 20 \mathrm{H}), 1.46-1.29(\mathrm{~m}, 40 \mathrm{H}) .{ }^{13} \mathrm{C}\right.$ $\operatorname{NMR}\left(100 \mathrm{MHz}, \mathrm{CDCl}_{3}\right): \delta[\mathrm{ppm}]=167.8,166.4,153.1,137.1,130.5,129.7,129.1,128.7,119.0,105.8,73.5$, 69.4, 64.8, 44.9, 37.4, 31.4, 30.4, 29.7, 29.6, 29.6, 29.4, 29.3, 29.3, 28.7, 29.1, 26.0. FT-IR (ATR): $v=3111$, 2916, 2850, 1723, 1643, 1582, 1496, 1467, 1410, 1338, 1296, 1187, 1114, 1093, 1055, 981, 869, 839, 809, 721, $667 \mathrm{~cm}^{-1}$. Elemental analysis calcd (\%) for $\mathrm{C}_{55} \mathrm{H}_{87} \mathrm{~N}_{3} \mathrm{O}_{10}: \mathrm{C}, 69.51, \mathrm{H}, 9.23, \mathrm{~N}, 4.42$; found: $\mathrm{C}, 69.61, \mathrm{H}$, 8.94, N, 4.46. HRMS (ESI): molecular weight: $950.3120\left(\mathrm{C}_{55} \mathrm{H}_{87} \mathrm{~N}_{3} \mathrm{O}_{10}\right) ; \mathrm{m} / \mathrm{z}$ calcd for $\left[\mathrm{C}_{55} \mathrm{H}_{88} \mathrm{~N}_{3} \mathrm{O}_{10}\right]^{+}$: $950.6464\left([\mathrm{M}+\mathrm{H}]^{+}\right)$; found: 950.6412 .

\section{Synthesis of Compound 1}

Compound $3(0.51 \mathrm{~g}, 0.54 \mathrm{mmol})$ was dissolved in dichloromethane $(5 \mathrm{~mL})$ in a light resistant container. Then, 1,3-propanesultone $(0.33 \mathrm{~g}, 2.69 \mathrm{mmol})$ was added dropwise. The reaction mixture was stirred at room temperature for 3 days. The crude product was purified by a silica gel chromatography (elution with $\mathrm{CHCl}_{3} / \mathrm{MeOH}=9 / 1$ ). Subsequent purification using a recycling preparative HPLC (eluent: $\left.\mathrm{CHCl}_{3}\right)$ afforded a white solid of compound $1(0.40 \mathrm{~g}, 0.37 \mathrm{mmol}, 69 \%$ yield $)$.

${ }^{1} \mathrm{H}$ NMR $\left(300 \mathrm{MHz}, \mathrm{CDCl}_{3}\right): \delta[\mathrm{ppm}]=9.76(\mathrm{~s}, 1 \mathrm{H}), 8.19(\mathrm{~d}, J=6.6 \mathrm{~Hz}, 1 \mathrm{H}), 7.18(\mathrm{~s}, 2 \mathrm{H}), 7.12$ $(\mathrm{s}, 1 \mathrm{H}), 6.39(\mathrm{dd}, J=17.2,1.5 \mathrm{~Hz}, 3 \mathrm{H}), 6.11(\mathrm{dd}, J=17.2,10.3 \mathrm{~Hz}, 3 \mathrm{H}), 5.81(\mathrm{dd}, J=10.4,1.6 \mathrm{~Hz}, 3 \mathrm{H}), 4.40$ $(\mathrm{m}, 4 \mathrm{H}), 4.14(\mathrm{t}, J=6.8 \mathrm{~Hz}, 6 \mathrm{H}), 4.04(\mathrm{t}, J=6.2 \mathrm{~Hz}, 3 \mathrm{H}), 3.96(\mathrm{t}, J=6.6 \mathrm{~Hz}, 1 \mathrm{H}), 3.52(\mathrm{~d}, J=5.1 \mathrm{~Hz}, 2 \mathrm{H})$, 
$2.78(\mathrm{~m}, 2 \mathrm{H}), 2.30(\mathrm{~d}, J=5.5 \mathrm{~Hz}, 4 \mathrm{H}), 1.82-1.61(\mathrm{~m}, 20 \mathrm{H}), 1.37(\mathrm{~d}, J=49.5 \mathrm{~Hz}, 42 \mathrm{H}) .{ }^{13} \mathrm{C} \mathrm{NMR}(100 \mathrm{MHz}$, $\left.\mathrm{CDCl}_{3}\right): \delta[\mathrm{ppm}]=167.9,166.4,152.9,140.7,130.5,129.1,128.7,122.2,121.8,106.1,73.5,69.3,64.8,47.2$, 29.8, 29.7, 29.6, 29.5, 29.4, 29.3, 28.7, 26.2, 26.0. FT-IR (ATR): $v=2918,2851,1721,1636,1579,1540,1497$, $1469,1409,1330,1296,1184,1113,1038,982,810,766,603,523 \mathrm{~cm}^{-1}$. Elemental analysis calcd (\%) for $\mathrm{C}_{58} \mathrm{H}_{93} \mathrm{~N}_{3} \mathrm{O}_{13} \mathrm{~S}: \mathrm{C}, 64.96, \mathrm{H}, 8.74, \mathrm{~N}, 3.92, \mathrm{~S}, 2.99$; found: $\mathrm{C}, 65.10, \mathrm{H}, 8.39, \mathrm{~N}, 3.85, \mathrm{~S}, 3.14$.

Synthesis of Protic Ionic Liquid 2

In a dry nitrogen atmosphere in a glove box, solid HTFSI $(2.04 \mathrm{~g}, 7.26 \mathrm{mmol})$ was added to solid imidazole $(0.494 \mathrm{~g}, 7.26 \mathrm{mmol})$ in a glass vial. The exothermic reaction immediately occurred and gave a colorless liquid. The obtained liquid was stirred for 5 minutes and turned to a white solid at an ambient temperature. The solid was recrystallized from a hot acetone. After filtration of the solid by a suction funnel under a nitrogen atmosphere, a white powder of 2 was dried under vacuum at $80{ }^{\circ} \mathrm{C}$ overnight $(2.322 \mathrm{~g}, 6.65 \mathrm{mmol}, 92 \%$ yield $) .{ }^{1} \mathrm{H}$ NMR $\left(300 \mathrm{MHz}, \mathrm{D}_{2} \mathrm{O}\right): \delta[\mathrm{ppm}]=8.73(\mathrm{~s}, 1 \mathrm{H})$, $7.53(\mathrm{~s}, 2 \mathrm{H}) .{ }^{13} \mathrm{C}$ NMR $\left(100 \mathrm{MHz}, \mathrm{D}_{2} \mathrm{O}\right): \delta[\mathrm{ppm}]=133.3,119.7(\mathrm{q}, J=318.2 \mathrm{~Hz}), 118.9$. FT-IR (ATR): $v=3266,1585,1340,1184,1127,1049,789,769,739,650,632,614,570,511 \mathrm{~cm}^{-1}$.

\section{Preparation of the LC Mixtures of $\mathbf{1}$ and $\mathbf{2}$}

The LC monomers composed of $\mathbf{1}$ and $\mathbf{2}$ with different molar ratios (M1/2(x), $\mathbf{x}$ denotes the mol\% of 2 in the mixtures) were prepared as follows. The solid samples of 1,2 , and $1.0 \mathrm{wt} \%$ 2,2-dimethyl-2-phenylacetophenone as a photoinitiator were mixed in anhydrous tetrahydrofuran. The solvent was slowly evaporated at $40^{\circ} \mathrm{C}$ in a light-resistant container. The resultant mixtures were dried in a vacuum oven at $35{ }^{\circ} \mathrm{C}$ for 48 hours. $15 \mathrm{wt} \%$ distilled water was added to the mixtures in a vial. Centrifugation of the mixtures $(13,500 \mathrm{rpm}, 14 \mathrm{~min})$ gave the lyotropic columnar liquid crystals at room temperature. Three mixtures of M1/2(40), M1/2(50), and M1/2(60) were used for the characterization of liquid crystallinity and ionic conductivity.

\subsection{Characterization of LC Properties}

The optical texture of LC mixtures was observed by using a polarizing optical microscope (POM) (Olympus BX51N-31P-O3, Olympus Corporation, Tokyo, Japan), equipped with a digital camera DP22 and a temperature control system (LINKAM T95-HS, LTS420E). X-ray diffraction (XRD) measurements were carried out by using a Rigaku MiniFlex 600 (Ni-filtered $\mathrm{Cu} \mathrm{K} \alpha$ radiation, Rigaku Corporation, Tokyo, Japan) diffractometer equipped with an Anton Par thermal control system BTS 500.

\subsection{Ionic Conductivity Measurements}

The measurement cell consists of a pair of indium tin oxide (ITO) coated glasses with a polyimide tape spacer with a hole of $3 \mathrm{~mm}$ punch diameter. The monomer was filled into the hole of the sandwich cell and polymerized by UV irradiation. The ionic conductivities of polymerized samples with LC and isotropic molecular arrangement were measured as a function of temperature by an alternating current impedance method, using a Metrohm Autolab PGSTAT128N (frequency: $100 \mathrm{~Hz}-10 \mathrm{MHz}$, applied voltage: $0.6 \mathrm{~V}$ ) with a temperature controller. The impedance data were fitted by the equivalent circuit consisting of a phase constant element and a parallel RC element. The ionic conductivities were calculated by the equation: $\sigma=d /(R \cdot S)$, where $\sigma$ is the conductivity $\left(\mathrm{S} \mathrm{cm}^{-1}\right), d$ is the sample thickness $(\mathrm{cm}), R$ is the bulk resistance $(\Omega)$, and $S$ is the area $\left(\mathrm{cm}^{2}\right)$ of sample. The value of $R$ was obtained from the intercept of the semicircle on the real axis of impedance in Nyquist plots.

\section{Results and Discussion}

\subsection{LC Properties}

Zwitterionic compound $\mathbf{1}$ alone in the dry state shows no thermotropic liquid crystallinity and exhibits the crystal-isotropic liquid transition at $90^{\circ} \mathrm{C}$ on heating. Protic ionic liquid 2 shows a melting 
point at $73{ }^{\circ} \mathrm{C}$ [19]. The monomeric mixtures of $\mathbf{1}$ and $\mathbf{2}$ in the dry state (M1/2(40), M1/2(50) and M1/2(60), the values in the parentheses are the mol\% of $\mathbf{2}$ in the mixture of $\mathbf{1}$ and 2) form isotropic liquids at ambient temperature. On the other hand, the addition of $15 \mathrm{wt} \%$ water to the mixtures has successfully induced the lyotropic columnar LC phases ( $\mathrm{Col}$ ) at ambient temperature. Fan-like textures assignable to a lyotropic columnar phase are observed for all mixtures under crossed polarizers, as shown in Figure 3. The LC texture is observed up to $100{ }^{\circ} \mathrm{C}$. The optical birefringence gradually disappears on further heating and the mixture eventually becomes the isotropic liquid state by the evaporation of water.

(a)

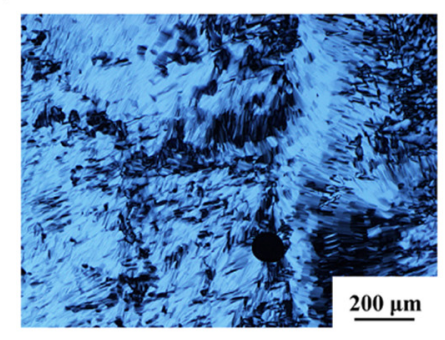

(b)

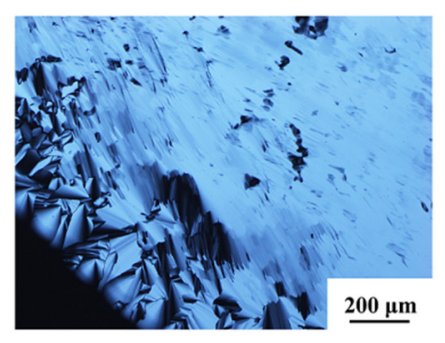

(c)

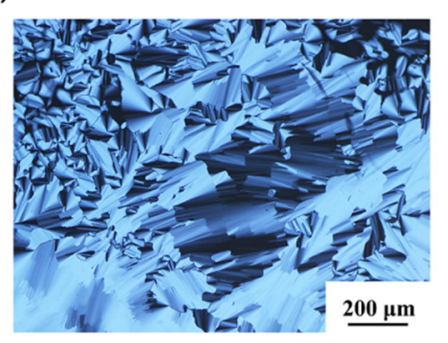

Figure 3. Polarizing optical micrographs of (a) M1/2(40) at $65^{\circ} \mathrm{C},(\mathbf{b}) \mathbf{M 1} / \mathbf{2}(\mathbf{5 0})$ at $80^{\circ} \mathrm{C},(\mathbf{c}) \mathbf{M 1} / \mathbf{2}(\mathbf{6 0})$ at $60^{\circ} \mathrm{C}$.

The interactions of $\mathbf{1}$ and $\mathbf{2}$ were examined by FT-IR measurements (Figure 4 ). The amide $\mathrm{N}-\mathrm{H}$ stretching peak at $3320 \mathrm{~cm}^{-1}$ of $\mathbf{1}$ is shifted to $3409 \mathrm{~cm}^{-1}$ by the addition of 2 . This result suggests that the intermolecular hydrogen bonds between the amide group weaken by an increase in the distance between the amide groups accompanied by the formation of an ion pair between the imidazolium cation of $\mathbf{1}$ and the TFSI anion of 2 and/or the formation of a hydrogen bond between the amide $\mathrm{N}-\mathrm{H}$ and the anion. In addition, M1/2(60) shows the C-H stretching band of the imidazolium ring at $3153 \mathrm{~cm}^{-1}$, which is in the almost same position as that observed for $\mathbf{2}$, whereas zwitterion $\mathbf{1}$ showed three $\mathrm{C}-\mathrm{H}$ stretching peaks between 3000 and $3200 \mathrm{~cm}^{-1}$. These results also support the pairing of the imidazolium cation of $\mathbf{1}$ with the TFSI anion of $\mathbf{2}$. Moreover, the $\mathrm{C}-\mathrm{SO}_{2}-\mathrm{N}$ absorption peak [20] at $1127 \mathrm{~cm}^{-1}$ of 2 is shifted to $1136 \mathrm{~cm}^{-1}$ upon the addition of $\mathbf{1}$. This high-wavenumber shift may be caused by the weakening of the interaction associated with the ion-pairing between the imidazolium ring of $\mathbf{1}$ and the TFSI anion of 2, compared to that of the protonated imidazole of $\mathbf{2}$ and the anion. On the other hand, the $\mathrm{C}=\mathrm{O}$ stretching bands of $\mathbf{1}$ and $\mathbf{M 1} / \mathbf{2}(\mathbf{6 0})$ were observed at 1722 and $1718 \mathrm{~cm}^{-1}$, respectively. This result indicates that the $\mathrm{C}=\mathrm{O}$ group of $\mathbf{1}$ is not involved in the interactions between 2 .

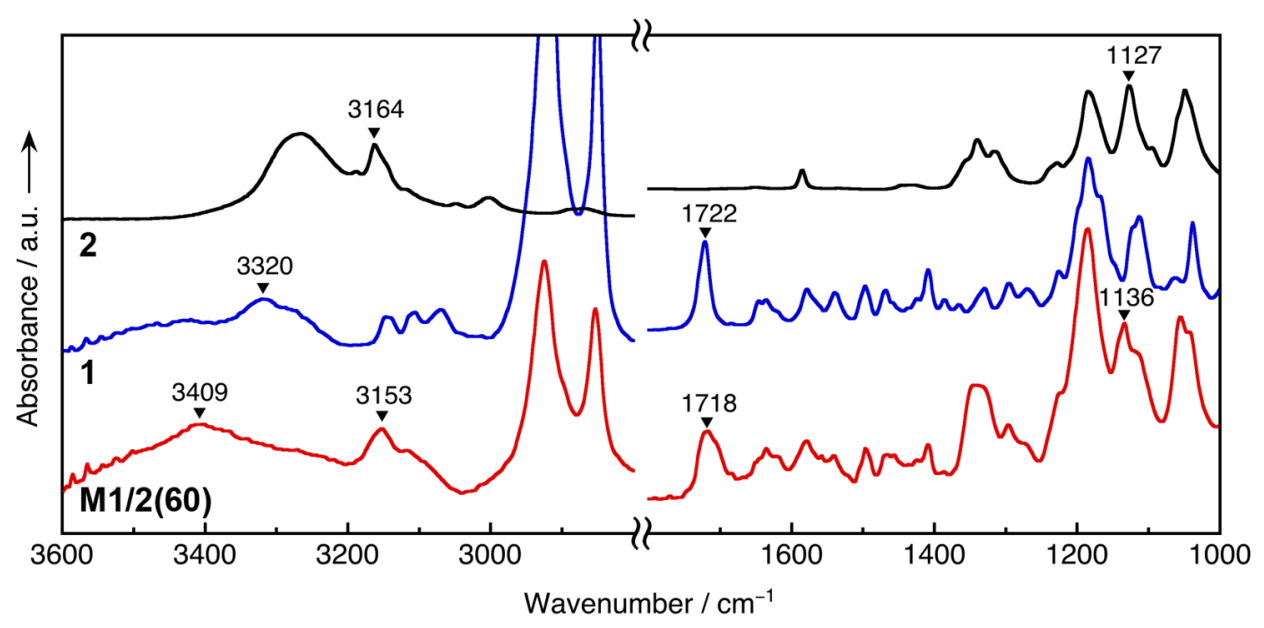

Figure 4. FT-IR spectra of 2 (black line), 1 (blue line), and M1/2 (60) (red line) at room temperature. 


\subsection{In Situ Photopolymerization of the LC Monomers}

In situ photopolymerization of the LC mixtures was carried out to obtain ion-conductive polymer films preserving the columnar nanostructures. The monomeric LC mixtures M1/2(40), M1/2(50), and M1/2(60) containing $1.0 \mathrm{wt} \%$ 2,2-dimethyl-2-phenylacetophenone as a photoinitiator were sandwiched between two indium tin oxide (ITO) glasses and the thickness was controlled by a polyimide spacer. The UV light irradiation ( $365 \mathrm{~nm}, 30 \mathrm{~mW} \mathrm{~cm}^{-2}$ ) with a Xenon lamp for $10 \mathrm{~min}$ was performed for the polydomain sample in the Col phase at room temperature. This irradiation led to the formation of a translucent free-standing polymer film (Figure 5a). No significant change in the columnar alignment is observed after polymerization under POM observation (Figure 5b). The UV polymerization was confirmed by FT-IR measurements. The $\mathrm{C}=\mathrm{C}$ absorption band of acrylate moiety was observed at $811 \mathrm{~cm}^{-1}$ for the monomeric M1/2(60). In contrast, the polymer film of $\mathbf{P 1 / 2 ( 6 0 )}$ obtained after UV irradiation shows no $\mathrm{C}=\mathrm{C}$ absorption peak (Figure $5 \mathrm{c}$ ).

(a)

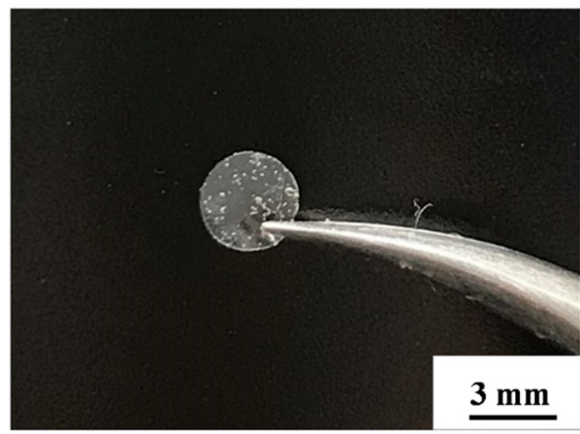

(c)

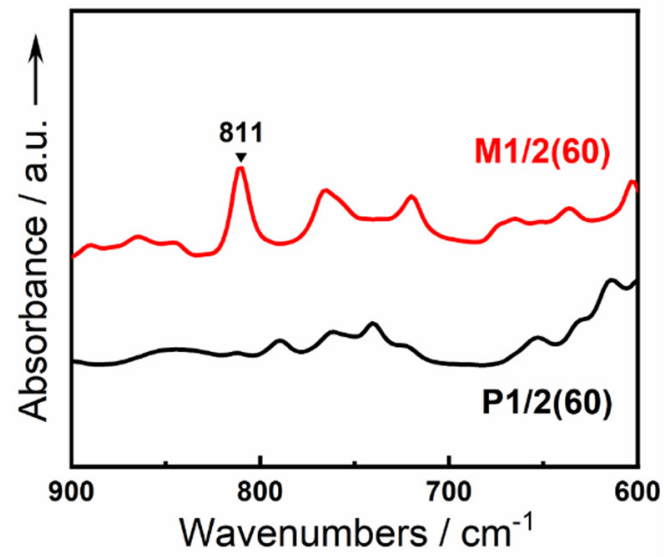

(b)

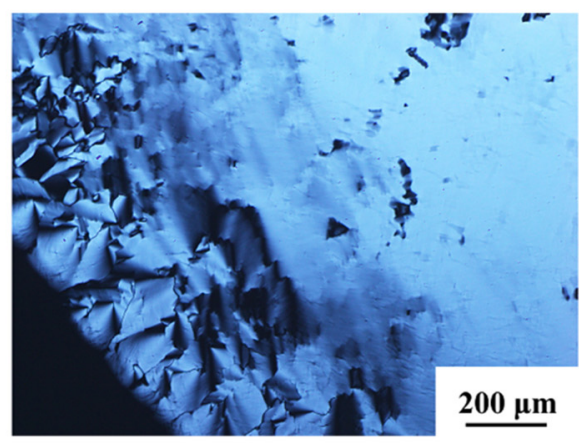

(d)

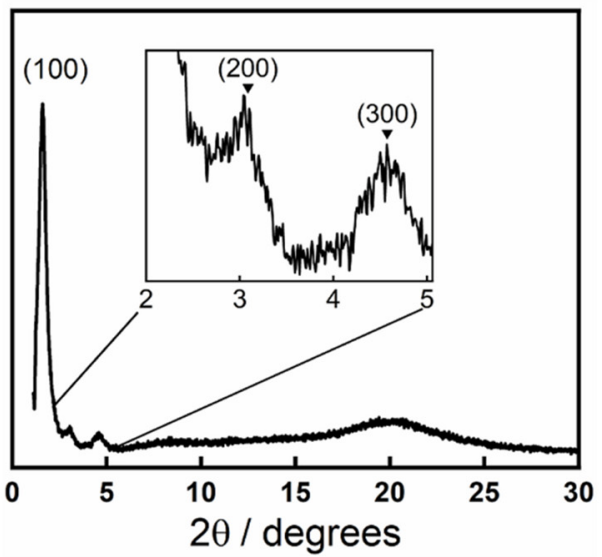

Figure 5. (a) Photograph of a free-standing polymer film of $\mathbf{P 1 / 2 ( 6 0 )}$ at room temperature. The thickness is $458 \mu \mathrm{m}$. (b) POM image of P1/2(50). (c) FT-IR spectra of M1/2(60) and P1/2(60). (d) XRD pattern of P1/2(50) at room temperature.

The XRD pattern of the P1/2(50) at room temperature shows three peaks at $55.9\left(2 \theta=1.58^{\circ}\right)$, $29.6\left(2.98^{\circ}\right)$, and $19.1 \AA\left(4.62^{\circ}\right)$ (Figure $5 \mathrm{~d}$ ). These peaks are assumed to be the (100), (200), and (300) reflections of a columnar arrangement, respectively although the $d$-spacing ratio does not exactly match $1: 1 / 2: 1 / 3$. Assuming that the polymer films formed a hexagonal columnar structure, the intercolumnar distance ( $a$ ) was calculated to be $66 \AA$ by the following equation: $a=2<d_{100}>/ \sqrt{ } 3,<d_{100}>=\left(d_{100}+2\right.$ $\left.d_{200}+3 d_{300}\right) / 3$. The number $(n)$ of molecules per unit cell in a hexagonal lattice was estimated to be approximately 14 according to the equation: $n=\left(\sqrt{3} N_{A} a^{2} h \rho\right) / 2 M$, where $N_{A}$ is Avogadro's number $\left(6.02 \times 10^{23} \mathrm{~mol}^{-1}\right), h$ is the average height of the stratum of a column $\left(4.45 \AA\right.$ from a halo peak at $\left.19.9^{\circ}\right)$, 
$M$ is the average molecular weight of $\mathbf{M 1 / 2 ( 5 0 )}\left(M=710.84 \mathrm{~g} \mathrm{~mol}^{-1}\right)$, and the density $(\rho)$ was assumed to be $1.0 \mathrm{~g} \mathrm{~cm}^{-3}$.

An increase in the amount of protic ionic liquid 2 in the mixture tends to decrease the intercolumnar distance rather than column expansion. The $a$ values of $\mathbf{P 1 / 2 ( 4 0 ) , ~ P 1 / 2 ( 5 0 ) , ~ a n d ~} \mathbf{P 1 / 2 ( 6 0 )}$ are estimated to be 68,66 , and $64 \AA$, respectively. These results also suggest that the protic ionic liquid dissociates and forms an ion pair with the zwitterionic moiety, organized into the center of columns. The increase in the electrostatic and hydrogen-bonded interactions results in column shrinkage.

\subsection{Ion-Conductive Properties of Polymer Films}

In order to clarify the influence of polymer nanostructures on ionic conductivity, amorphous polymer films were prepared by photopolymerization of M1/2(40), M1/2(50), and M1/2(60) in an isotropic liquid state (P1/2(x)-Iso). Figure 6 shows the temperature dependence of ionic conductivities for P1/2(x), with the columnar nanostructures and amorphous P1/2(x)-Iso. The ionic conductivity for all samples increases with the increase in temperature due to the thermal activation of the molecular motility. The increase of the protic ionic liquid content in the mixtures leads to the enhancement of ionic conductivities because of the increase in the number of ionic carriers. It is significant that nanostructured polymers P1/2(x) exhibits 100-1000 times higher conductivities than the corresponding amorphous polymers P1/2(x)-Iso. For example, the conductivity value of $\mathbf{P 1 / 2 ( 6 0 )}$ is $4.2 \times 10^{-4} \mathrm{~S} \mathrm{~cm}^{-1}$ at $20^{\circ} \mathrm{C}$, which is 1000 times higher than $\mathbf{P 1 / 2 ( 6 0 )}$-Iso at the same temperature $\left(4.5 \times 10^{-7} \mathrm{~S} \mathrm{~cm}^{-1}\right)$. These results suggest that the formation of ionic nanochannels is essential to enhance ion transport in the solid polymer matrices. The maximum conductivity reaches $3.0 \times 10^{-3} \mathrm{~S} \mathrm{~cm}^{-1}$ at $80^{\circ} \mathrm{C}$ for P1/2(60). Protic ionic liquid 2 was reported to show the proton conductivity of $2.7 \times 10^{-2} \mathrm{~S} \mathrm{~cm}^{-1}$ at $130{ }^{\circ} \mathrm{C}$ [19]. It is worthwhile to note that high ion-conductive and flexible solid polymer electrolytes could be obtained by self-assembly of the solid protic salt, the insulating zwitterionic monomer, and a small amount of water.

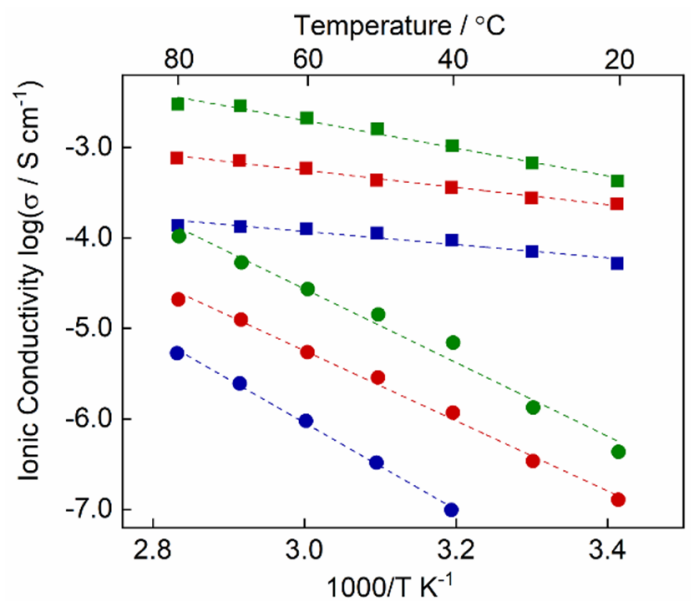

Figure 6. Ionic conductivities of polymers 1/2(40) (blue), 1/2(50) (red), and 1/2(60) (green) with Col LC molecular arrangement (square) and isotropic molecular arrangement (round). The dashed lines are fit by the Arrhenius equation to the data.

The temperature-dependent ionic conductivity ( $\sigma$ ) can be fitted by the Arrhenius equation, $\sigma=\sigma_{0}$ $\exp \left(-E_{a} / R T\right)$, where $R$ is a gas constant and $T$ is the temperature in Kelvin. The activation energies $\left(E_{a}\right)$ of $\mathbf{P 1 / 2 ( 6 0 )}$ and $\mathbf{P 1 / 2 ( 6 0 )}$-Iso were estimated from the slope $\left(-E_{a} / R\right)$ of lines to be $13 \mathrm{~kJ} \mathrm{~mol}^{-1}$ and $28 \mathrm{~kJ} \mathrm{~mol}^{-1}$, respectively. The lower activation energy for P1/2(60) is attributed to the formation of continuous hydrogen-bonded networks consisting of the protonated imidazole, the sulfonate anion of 2, and water. More interestingly, the $E_{a}$ value of $\mathbf{P 1 / 2}(\mathbf{x})$ tends to decrease with the decrease in the protic ionic liquid content. The $E_{a}$ values of $\mathbf{P 1 / 2 ( 5 0 )}$ and $\mathbf{P 1 / 2 ( 4 0 )}$ are 7.9 and $6.1 \mathrm{~kJ} \mathrm{~mol}^{-1}$, respectively. 
These results indicate that the introduction of proton accepting vacant sites is a great key to constitute the effective proton-conductive pathways in the LC polymers.

Recently, Ichikawa and coworkers developed proton-conductive bicontinuous cubic LC polymer films, based on the self-assembly of polymerizable zwitterionic molecules and HTFSI in the presence of water [16]. The three-dimensionally continuous channel structures allowed significantly higher proton conduction of $9.9 \times 10^{-2} \mathrm{~S} \mathrm{~cm}^{-1}$ at $70{ }^{\circ} \mathrm{C}$ and lower activation energy of $2.2 \mathrm{~kJ} \mathrm{~mol}^{-1}$ attributable to proton conduction via the Grotthuss mechanism. Our materials presented herein show two orders of magnitude lower conductivities. The difference in ionic conductivity between columnar and bicontinuous cubic zwitterionic LC polymers seems to be mainly due to the differences in channel connectivity, proton conduction mechanism, and size of mobile ions. Bicontinuous cubic LC assemblies have the advantage of channel connectivity without alignment control. However, uniaxially oriented columnar LC channels are expected to show faster ion transport ability due to their linearity. In the present study, we could not achieve the vertical alignment of the columnar structures across the polymer films. These oriented materials have great potentials for the development of ion-conductive polymer actuators that can achieve both high speed oscillation and high-power generation. For such application, fast transport of large ions is required. In this context, by employing hydrated and protonated imidazole as cation species, we have succeeded in the fabrication of mechanically robust nanostructured polymer films exhibiting good ionic conductivities in the order of $10^{-4}-10^{-3} \mathrm{~S} \mathrm{~cm}^{-1}$ at ambient temperature. Our findings will provide a basis for opening up new applications of ion-conductive LC materials.

\section{Conclusions}

We have designed a new columnar LC self-assembly of polymerizable zwitterionic compound, consisting of an imidazolium sulfobetaine moiety and protic ionic liquid in the presence of small amount of water. In situ photopolymerization of the columnar LC mixtures resulted in the mechanically stable and free-standing polymer films preserving the columnar nanostructures. The polymer films with polydomain columnar orientation exhibited good ionic conductivity, in the order of $10^{-4}-10^{-3} \mathrm{~S} \mathrm{~cm}^{-1}$ at ambient temperature. The nanostructured polymers showed 100-1000 times higher conductivity, compared to the corresponding amorphous polymer films. Control of the number of vacancy sites consisting of the sulfonate anion is of importance for efficient proton transport. Two-component noncovalent approach for the development of ionic LC materials has advantages not only for tuning the ion transport properties, but also for optimizing nanostructures and temperature range of LC phases. Nanostructured ion-conductive polymer films have great potential for applications such as fuel cells, filtration membranes, and polymer actuators.

Author Contributions: Conceptualization, M.Y.; methodology, M.Y.; validation, S.C., A.S. and M.Y.; formal analysis, S.C.; investigation, S.C. and M.Y.; resources, M.Y.; data curation, S.C. and M.Y.; writing-original draft preparation, S.C.; writing—review and editing, S.C., A.S. and M.Y.; visualization, S.C. and M.Y.; supervision, M.Y.; funding acquisition, M.Y. All authors have read and agreed to the published version of the manuscript.

Funding: This study was partially supported by a Grant-in-Aid for Scientific Research (B) (No. 17H03064) from JSPS for M.Y. and the joint research expenses from the Nissan Chemical Corporation.

Acknowledgments: The authors thank M. Takeuchi and A. Takai at National Institute for Materials Science for help with the High-Resolution Mass Spectrometry (HRMS) measurements.

Conflicts of Interest: The authors declare no conflict of interest.

\section{References}

1. Kato, T.; Yoshio, M.; Ichikawa, T.; Soberats, B.; Ohno, H.; Funahashi, M. Transport of ions and electrons in nanostructured liquid crystals. Nat. Rev. Mater. 2017, 2, 17001. [CrossRef]

2. Ichikawa, T.; Kato, T.; Ohno, H. Dimension control of ionic liquids. Chem. Commun. 2019, 55, 8205-8214. [CrossRef] [PubMed]

3. Ichikawa, T. Zwitterions as building blocks for functional liquid crystals and block copolymers. Polym. J. 2017, 49, 413-421. [CrossRef] 
4. Cho, B.-K. Nanostructured organic electrolytes. RSC Adv. 2014, 4, 395-405. [CrossRef]

5. Wang, C.; Cao, S.; Li, P.; Tan, S.; Wu, Y. Anisotropic films photopolymerized from aligned cross-linkable gemini ammonium liquid crystals for ion conduction. J. Appl. Polym. Sci. 2019, 136, 47349. [CrossRef]

6. Hamaguchi, K.; Kuo, D.; Liu, M.; Sakamoto, T.; Yoshio, M.; Katayama, H.; Kato, T. Nanostructured Virus Filtration Membranes Based on Two-Component Columnar Liquid Crystals. ACS Macro Lett. 2018, 8, 24-30. [CrossRef]

7. Henmi, M.; Nakatsuji, K.; Ichikawa, T.; Tomioka, H.; Sakamoto, T.; Yoshio, M.; Kato, T. Self-organized Liquid-Crystalline Nanostructured Membranes for Water Treatment: Selective Permeation of Ions. Adv. Mater. 2012, 24, 2238-2241. [CrossRef] [PubMed]

8. Bara, J.E.; Kaminski, A.K.; Noble, R.D.; Gin, D.L. Influence of nanostructure on light gas separations in cross-linked lyotropic liquid crystal membranes. J. Memb. Sci. 2007, 288, 13-19. [CrossRef]

9. Kim, O.; Kim, H.; Choi, U.H.; Park, M.J. One-volt-driven superfast polymer actuators based on single-ion conductors. Nat. Commun. 2016, 7, 13576. [CrossRef] [PubMed]

10. Yamashita, A.; Yoshio, M.; Soberats, B.; Ohno, H.; Kato, T. Use of a protic salt for the formation of liquid-crystalline proton-conductive complexes with mesomorphic diols. J. Mater. Chem. A 2015, 3, 22656-22662. [CrossRef]

11. Soberats, B.; Yoshio, M.; Ichikawa, T.; Taguchi, S.; Ohno, H.; Kato, T. 3D Anhydrous Proton-Transporting Nanochannels Formed by Self-Assembly of Liquid Crystals Composed of a Sulfobetaine and a Sulfonic Acid. J. Am. Chem. Soc. 2013, 135, 15286-15289. [CrossRef] [PubMed]

12. Yoshizawa, M.; Ohno, H. Anhydrous proton transport system based on zwitterionic liquid and HTFSI. Chem. Commun. 2004, 16, 1828-1829. [CrossRef] [PubMed]

13. Ichikawa, T.; Kato, T.; Ohno, H. 3D Continuous Water Nanosheet as a Gyroid Minimal Surface Formed by Bicontinuous Cubic Liquid-Crystalline Zwitterions. J. Am. Chem. Soc. 2012, 134, 11354-11357. [CrossRef] [PubMed]

14. Ueda, S.; Kagimoto, J.; Ichikawa, T.; Kato, T.; Ohno, H. Anisotropic proton-conductive materials formed by the self-organization of phosphonium-type zwitterions. Adv. Mater. 2011, 23, 3071-3074. [CrossRef] [PubMed]

15. Ichikawa, T.; Okafuji, A.; Kato, T.; Ohno, H. Induction of an Infinite Periodic Minimal Surface by Endowing An Amphiphilic Zwitterion with Halogen-Bond Ability. ChemistryOpen 2016, 5, 439-444. [CrossRef] [PubMed]

16. Kobayashi, T.; Li, Y.; Ono, A.; Zeng, X.; Ichikawa, T. Gyroid structured aqua-sheets with sub-nanometer thickness enabling 3D fast proton relay conduction. Chem. Sci. 2019, 10, 6245-6253. [CrossRef] [PubMed]

17. Yasuda, T.; Watanabe, M. Protic ionic liquids: Fuel cell applications. MRS Bull. 2013, 38, 560-566. [CrossRef]

18. Smith, R.C.; Fischer, W.M.; Gin, D.L. Ordered Poly(p-phenylenevinylene) Matrix Nanocomposites via Lyotropic Liquid-Crystalline Monomers. J. Am. Chem. Soc. 1997, 119, 4092-4093. [CrossRef]

19. Susan, M.A.B.H.; Noda, A.; Mitsushima, S.; Watanabe, M. Brønsted Acid-Base Ionic Liquids and Their Use as New Materials for Anhydrous Proton Conductors. Chem. Commun. 2003, 8, 938-939. [CrossRef] [PubMed]

20. Wu, A.; Lu, F.; Sun, P.; Qiao, X.; Gao, X.; Zheng, L. Low-Molecular-Weight Supramolecular Ionogel Based on Host-Guest Interaction. Langmuir 2017, 33, 13982-13989. [CrossRef] [PubMed]

(C) 2020 by the authors. Licensee MDPI, Basel, Switzerland. This article is an open access article distributed under the terms and conditions of the Creative Commons Attribution (CC BY) license (http://creativecommons.org/licenses/by/4.0/). 